\title{
Erratum to: Reaction of 4-Halo-3-hydroxyfuro[3,4-c]pyridin- 1(3H)-ones with Morpholine and Thiomorpholine Synthesis and Antimicrobial Activity
}

\author{
S. V. Fedoseev ${ }^{a} * *$ and O. V. Ershov ${ }^{a}$ \\ ${ }^{a}$ I.N. Ul'yanov Chuvash State University, Cheboksary, 428015 Russia \\ *e-mail:sergey.fedoseev88@gmail.com
}

Received July 25, 2021; revised July 25, 2021; accepted July 25, 2021

DOI: $10.1134 / \mathrm{S} 1070428021080194$

The name of second author should read as O. V. Ershov.

The original article can be found online at https://doi.org/10.1134/S1070428021030234 